See discussions, stats, and author profiles for this publication at: https://www.researchgate.net/publication/347833970

\title{
A pig slurry feast/famine feeding regime strategy to improve mesophilic anaerobic digestion efficiency and digestate hygienisation
}

Article in Waste Management \& Research · December 2020

DOI: $10.1177 / 0734242 \times 20972794$

\section{CITATION}

4 authors:

Inês Silva

University of Lisbon

1 PUBLICATION 1 CITATION

SEE PROFILE

Luisa Brito

University of Lisbon

55 PUBLICATIONS 673 CITATIONS

SEE PROFILE
READS

37

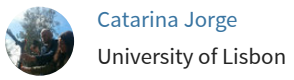

2 PUBLICATIONS 1 CITATION

SEE PROFILE

(E)

Elizabeth Costa Neves Fernandes D'Almeida Duarte

University of Lisbon

102 PUBLICATIONS 1,499 CITATIONS

SEE PROFILE

Some of the authors of this publication are also working on these related projects:

Project $\quad$ ProEnergy - Novos produtos alimentares e bioenergia a partir de frutos de baixo valor comercial e resíduos agroindustriais View project

Project Valorization of ovine cheese whey View project 


\title{
A pig slurry feast/famine feeding regime strategy to improve mesophilic anaerobic digestion efficiency and digestate hygienisation
}

Waste Management \& Research 1-9

(c) The Author(s) 2020 Article reuse guidelines:

sagepub.com/journals-permissions DOI: 10.1177/0734242X20972794 journals.sagepub.com/home/wmr @SAGE

\author{
I Silva ${ }^{1}$, , C Jorge ${ }^{2,3}$, L Brito ${ }^{1}$ and E Duarte ${ }^{1}$
}

\begin{abstract}
The increasing concentration of livestock farms results in large amounts of waste production and the need for their management. The study of anaerobic digestion (AD) technology, under mesophilic conditions, applied to pig slurry is of the upmost importance for biogas recovery and sanitised digestate, contributing to a circular economy. The assessment of the effects of a feast/famine regime on biogas and biomethane (bio- $\mathrm{CH}_{4}$ ) yield with different feeding frequencies was performed. The evaluation was made in regards to three scenarios: the first is based on daily feeding (FR1); in the second, the feeding occurs once every two days (FR2); and in the third, the feeding happens once every three days (FR3). The results demonstrate that the biogas and methane yield increased by $34 \%$ and $37 \%$ between FR1 and FR3. The stability inside the reactor was maintained since specific loading energetic rate values did not exceed the recommended limit $\left(0.4 \mathrm{~d}^{-1}\right)$. It was also possible to conclude that the AD technology was efficient to sanitise the pig slurry, with the count of Escherichia coli going from $1 \times 10^{5}$ colony-forming units (CFU) $\mathrm{g}^{-1}$ to less than $100 \mathrm{CFU} \mathrm{g}^{-1}$, meeting the legal requirements for agricultural valorisation. The total anaerobic mesophile plate counts were significantly $(p<0.1)$ reduced from feeding to digestate, and the plate counts of Clostridia were significantly $(p<0.05)$ increased, reflecting the changes in the composition of the microbiota. The increasing yield in bio- $\mathrm{CH}_{4}$ in accordance with Clostridium counts suggests this genus as a positive microbiological key indicator of the AD performance.
\end{abstract}

\section{Keywords}

Anaerobic digestion (AD), circular bioeconomy, Clostridia, livestock, mesophilic conditions, pig slurry management

Received 22 April 2020, accepted 18 October 2020 by Editor in Chief Arne Ragossnig.

\section{Introduction}

The continued use of fossil fuels and the impact of greenhouse gas (GHG) emissions has encouraged research into renewable energy production from biowastes and the implementation of economic models based on a circular economy - a system that is based on the recovery of materials, reuse, valorisation and recycling of natural cycles (Chojnacka et al., 2020).

Biogas production plays a major role in waste management and valorisation contributing to mitigate climate change. Biogas can be purified and upgraded, leading to biomethane (bio- $\mathrm{CH}_{4}$ ), which can be burned as a clean energy source in comparison with the conventional ones, particularly coal, providing energy needs with reduced levels of carbon dioxide emissions into the atmosphere (Achinas et al., 2017).

Anaerobic digestion (AD) is a biowaste-to-energy technology with a high potential for sustainable production (Srisowmeya et al., 2019). AD has multiple environmental advantages: the production of renewable biogas, the elimination of odour, the sanitisation of digestate and the reduction of GHG emissions (Shi et al., 2018, Wainaina et al., 2020). This technique can be a favourable method for achieving a circular economy, closing the cycle of nutrients and promoting biofertiliser production (Chojnacka et al., 2020, Wainaina et al., 2020).

In Portugal, a closed-cycle is the most common system for pig production, which includes all of the pig life stages. Animals are kept in housing facilities with specific conditions needed for each life stage, and the manure produced along the cycle is collected in a pit inside the housing that also receives wastewater from cleaning the room's facility. Manure composition resulting from different growing stages is highly dependent on the feeding

'LEAF - Linking Landscape, Environment, Agriculture and Food, Instituto Superior de Agronomia, Universidade de Lisboa, Tapada da Ajuda, Lisbon, Portugal

${ }^{2}$ Luke - Natural Resources Institute Finland, Helsinki, Finland ${ }^{3} \mathrm{CEF}$ - Forest Research Center, Instituto Superior de Agronomia, Universidade de Lisboa, Tapada da Ajuda, Lisbon, Portugal

\section{Corresponding author:}

E Duarte, LEAF - Linking Landscape, Environment, Agriculture and Food, Instituto Superior de Agronomia, Universidade de Lisboa,

Tapada da Ajuda, Lisbon, 1349-017, Portugal.

Email: eduartedisa.ulisboa.pt 
regime (FR), the animal's nutrient metabolic capacity, the conditions under which they are kept and the amount of water used for cleaning operations (Boyd et al., 2002, Zhang et al., 2014).

The continuous development and increasing concentration of livestock farms have resulted in large amounts of biowaste production. The manure produced requires proper management to prevent severe consequences to the environment, with the disposal/management of large amounts of manure generated being a great challenge to the swine industry (Bres et al., 2018). Physical, chemical and microbiological characteristics associated with the large volumes produced daily limit its direct use in agriculture (e.g. malodour and the presence of pathogens). The national regulation in Portugal is in compliance with the European regulation on microbiological criteria for fertilising products: absence of Salmonella in $25 \mathrm{~g}$ and less than 1000 colony-forming units (CFU) of Escherichia coli per $\mathrm{g}$ of fresh material (Regulation (EU) 2019/1009). Hence, the inadequate management of these biowastes can pose considerable risks to human and animal health, crops and the general environment (Ros et al., 2017). With inherent energy and fertiliser values of pig manure, AD is regarded as one of the best process engineering solutions to minimise waste and recover energy, partially overcoming manure's limitations and, at the same time, contributing to the circular economy model, where waste management plays a key role (Lopes et al., 2017; Zhang et al., 2014).

One of the major challenges posed by $\mathrm{AD}$ is to know the response of the microbial community inside the digester to different operational conditions (Lv et al., 2019). Several researchers have identified the composition of a microbial community as one of the most important factors to ensure functional stability in $\mathrm{AD}$ systems (Ros et al., 2017). It has been demonstrated that a high diversity of the bacterial community increases biogas production, probably by providing greater functional redundancy (Lin et al., 2016). The presence of obligatory/facultative anaerobes is fundamental for the $\mathrm{AD}$ process to occur, and the genus Clostridium, belonging to the phylum Firmicutes, is common to both. In fact, Firmicutes dominate the bacterial community during the stable performance of the $\mathrm{AD}$ process, with the genus Clostridium being the only one with relative abundance (over $5 \%$ ) at all stages of the process (Chen et al., 2016, De Jonge et al., 2017; Lin et al., 2016).

Different feeding frequencies may compromise the efficiency of the AD process; therefore, three FRs have been proposed, in order to evaluate the responses in terms of energy production and hygienisation of the digestate for nutrient recovery.

In this work, a new strategy for livestock effluent management is proposed - namely, the use of pig manure - specifically, from the fattening/finishing phase (FFM) of a closed pig cycle. Manure collection was carried out in this dedicated pig life stage, since it has a higher organic content, which it is expected to optimise the potential of biogas production, as stated by Duarte et al. (2020). The main objective of this study was to investigate the reactor feeding frequency with this type of slurry and, consequently, the effect of feast/famine on AD efficiency correlated with the digestate hygienisation degree.

\section{Material and methods}

\section{Origin and collection of pig manure}

Pig manure was sourced from a swine livestock facility located in the Santarém District, Portugal (38.6848969, -8.9647142), with a total area of 384.12 ha and capacity for 900 sows, with 3924 fattening places. This facility works in a closed-cycle operation, and the production is divided into four stages: gestation, farrowing, weaning and fattening/finishing.

The manure produced was collected in pits inside housing facilities, whenever needed or when the animals leave the room, and pits were emptied to a reception tank with stirring. Regarding the experimental assay design, all the pig manure samples were collected inside the fattening/finishing rooms to obtain a representative slurry from the pig fattening/finishing stage. Samples had traces of grains and coarse material, so the slurries were sieved in a strainer with a mesh size of $2 \mathrm{~mm}$, and after pre-treatment, the remaining liquid fractions were stored at $4{ }^{\circ} \mathrm{C}$.

\section{$A D$ experiment trials}

The AD experiment was performed under mesophilic conditions $\left(36.0-37.4^{\circ} \mathrm{C}\right)$ with the temperature inside the reactor being maintained by a heating system, during three FRs (FR1, FR2, FR3), with a hydraulic retention time (HRT) of 15 days. The experiment was carried out in a continuous stirred-tank reactor with a working volume of $4.8 \mathrm{~L}$, controlled by computer software. The agitation inside the digester was performed with a mechanical stirrer (VELP Scientifica, $50 \mathrm{rpm}, 60 \mathrm{~W}$ ) and feeding of the reactor was realised through a feed pump (Watson Marlow, $120 \mathrm{rpm})$. The biogas production was measured by a flow meter (MilliGascounter, Ritter, Germany).

\section{FRs}

After the steady state conditions were achieved, three FRs were performed continuously in the same $\mathrm{AD}$ reactor, during two HRTs (15 days) for each trial.

In the first FR, codified by FR1, the reactor was fed daily, which is considered the control trial. To evaluate the reactor response to fast and famine conditions, two feeding load patterns were designed: in FR2, the feeding load was carried once every two days; while in the FR3, the feeding occurs once every three days.

\section{Performance and stability parameters}

During the three regimes, the HRT and the organic loading rate were kept at 15 days and $1.50 \pm 0.06 \mathrm{~g}$ total volatile solids (TVS) L reactor ${ }^{-1} \mathrm{~d}^{-1}$, respectively.

Stability parameters ( $\mathrm{pH}$ and electrical conductivity) and performance (daily biogas production) of the AD process, as well as the feed (input) and digestion (output) flows, were monitored according to each regime's previously defined operational conditions. In addition, other parameters were determined periodically: biogas quality, 
measured on a weekly basis, through a connection of the reactor biogas flux bypass to an analyser (LMSxi Multifunction Landfill Gas Analyser); gas production rate (GPR); specific gas production (SGP); and specific methane production (SMP). At the beginning and end of each trial, total solids (TS), TVS, total chemical oxygen demand (TCOD), soluble chemical oxygen demand (SCOD), TVS and TCOD reduction, ammoniacal nitrogen and Kjeldahl nitrogen were determined according to the American Public Health Association (APHA, 2012). In order to evaluate the reactor stability, the specific energetic loading rate (SELR) was also determined. All the analyses were done in two or three replicates, and the results are presented with the mean values and their standard deviation.

\section{Microbiological analyses}

In order to evaluate the ability of the mesophilic AD to sanitise the digestate, Salmonella and E. coli were analysed in the FFM used to feed the reactor and in the resulting digestate. Salmonella detection was done according to International Organization for Standardization (ISO) 6579-1:2017. The enumeration of E. coli was according to ISO 16649-3:2015 using TBX medium (Biokar, Beauvais, France) and incubation at $44^{\circ} \mathrm{C} \pm 1^{\circ} \mathrm{C}$ for $24 \mathrm{~h}$.

The evolution of Clostridium spp. and of total anaerobic mesophiles according to the three FRs was also investigated in the FFM used to feed the reactor and in the resulting digestate. For the enumeration of Clostridium spp., TSN medium (Biokar, Beauvais, France) was used. Plates were incubated at $36^{\circ} \mathrm{C} \pm 1{ }^{\circ} \mathrm{C}$ for $72 \mathrm{~h}$. For the total anaerobic mesophile enumeration, two growth media were used: a nutritionally rich medium (TSAYE, Biokar, Beauvais, France) and a nutritionally poorer medium (MHA, Biokar, Beauvais, France), both with incubation periods of $24-72 \mathrm{~h}$, at $36^{\circ} \mathrm{C} \pm 1^{\circ} \mathrm{C}$. Incubations were conducted in anaerobiosis jars (Oxoid AnaeroJar 2.5L), with anaerobiosis sachets (GENbox anaer, Biomérieux, Marcy-l'Étoile, France) and indicator tapes (Anaer indicator, Biomérieux, Marcy-l'Étoile, France) to confirm the anaerobiosis in the jars.

\section{Statistical analysis}

Biogas. Statistical analysis was conducted in $\mathrm{R}$ software $(\mathrm{R}$ Core Team, 2019) with the 'car' package (Fox and Weisberg, 2019). Measurements were separated by FR and analysed for distribution using boxplots.

A one-way analysis of variance (ANOVA) with $\alpha=0.05$ was used to compare any significant differences in mean between groupings of the factor variable. Tukey's honestly significant difference (HSD) with $\alpha=0.05$ was then used to identify where those differences reside. The assumptions of normality and constant variance were verified by the Shapiro-Wilk and Levene tests, respectively. Normality violations were further explored through plots of residuals.

Since the homogeneity of variance assumption failed, even after removal of outliers, the Welch one-way test, which does not assume equal variances, was chosen to compare only FR2 and FR3, as it is in these regimes that a famine period is induced.
Microorganisms. The same tools and procedures used for biogas data were used for microbiological counting data. Measurements were, however, transformed into logarithmic value and then separated by feeding and digestate regime.

$\operatorname{ANOVA}(\alpha=0.05)$ was first used, followed by $\operatorname{HSD}(\alpha=0.05)$, to identify differences in average values. The assumptions of normality and constant variance were investigated as for biogas data.

Because the homogeneity of variance assumption failed frequently, the Welch one-way test was chosen to verify the initial findings of ANOVA. The Welch test always agreed with ANOVA, except at a different significance level. In a conservative approach, the $p$-value was increased to 0.1 , due not only to the violation of constant variance but also to the low number of observations for each analysis.

\section{Results and discussion}

\section{Feeding mixture and digestate characterisation}

Table 1 presents the results concerning the characterisation of the feedings and digestates of the trials performed.

The values presented in Table 1 for TS/TVS ratio had a small variation throughout the three regimes, with a mean value of $72.3 \pm 0.2 \%$, which is close to the values found in the literature: $75.69 \%$ (Yang et al., 2019). There is a slight increase in the SCOD/ TCOD ratio over feedings from various regimes, with a $9 \%$ increase between FR1 and FR2, followed by a $12 \%$ increase between FR1 and FR3. This increase suggests a higher bioavailability of the substrate for anaerobic microorganisms and, consequently, a higher biogas production. The total organic carbon efficiency removal along the experiment trials were $41 \%, 50 \%$ and $53 \%$, respectively, following the same behaviour of biogas yield.

During the AD trials, an increase in the carbon/nitrogen $(\mathrm{C} / \mathrm{N})$ ratio of $14 \%$ between FR1 and FR3 was observed, where the average of the $\mathrm{C} / \mathrm{N}$ ratio values was $7.5 \pm 0.5$, which is below the range of recommended values (20-30) for the AD process (Chiu et al., 2016; Kangle et al., 2011).

Analysing the $\mathrm{pH}$ profile of the feeds of the three regimes in study, it can be observed that they are within the recommended range (6.8-7.4) for the AD process (Khan et al., 2016; Lopes et al., 2017; Ning et al., 2019), with no large fluctuations in the digestate $\mathrm{pH}$ throughout the trials, remaining approximately between 7.4 and 8.0, as seen in Figure 1. Thus, the buffer capacity and the stability of the process are confirmed. Therefore, it can be concluded that there are no significant variations in $\mathrm{pH}$ values with the load shocks performed along the FRs.

\section{$A D$ stability and performance}

Analysing the values shown in Table 2, there was a gradual increase in daily biogas production according to the different FRs. For GP, there was a $20 \%$ increase from FR1 to FR2, followed by a $12 \%$ increase between FR2 and FR3, with an increase from FR1 to FR3 of about 34\%, as seen in Figure 2. For SMP, 
Table 1. Feeding and digestate characterisation.

\begin{tabular}{|c|c|c|c|c|c|c|}
\hline \multirow[t]{2}{*}{ Characteristics } & \multicolumn{2}{|l|}{ FR1 } & \multicolumn{2}{|l|}{ FR2 } & \multicolumn{2}{|l|}{ FR3 } \\
\hline & Influent & Digestate & Influent & Digestate & Influent & Digestate \\
\hline $\mathrm{pH}$ & $7.3 \pm 0.3$ & $7.6 \pm 0.1$ & $7.0 \pm 0.1$ & $7.8 \pm 0.0$ & $7.0 \pm 0.2$ & $7.8 \pm 0.1$ \\
\hline $\mathrm{EC}\left(\mathrm{mS} \mathrm{cm}^{-1}\right)$ & $12.2 \pm 0.6$ & $12.9 \pm 0.9$ & $12.8 \pm 0.3$ & $14.7 \pm 0.3$ & $13.1 \pm 0.3$ & $15.3 \pm 0.2$ \\
\hline TCOD $\left(\mathrm{g} \mathrm{kg}^{-1}\right)$ & $46.8 \pm 0.2$ & $29.0 \pm 2.9$ & $41.4 \pm 0.5$ & $19.0 \pm 0.8$ & $44.6 \pm 0.8$ & $16.6 \pm 3.0$ \\
\hline $\operatorname{SCOD}\left(\mathrm{g} \mathrm{kg}^{-1}\right)$ & $27.2 \pm 1.0$ & $9.8 \pm 1.5$ & $25.4 \pm 0.6$ & $5.8 \pm 0.1$ & $28.6 \pm 2.6$ & $4.8 \pm 0.5$ \\
\hline SCOD/TCOD (\%) & 58.0 & 34.0 & 63.0 & 31.0 & 65.0 & 30.0 \\
\hline TS $\left(g_{k g}{ }^{-1}\right)$ & $30.3 \pm 1.2$ & $19.7 \pm 0.8$ & $31.8 \pm 0.6$ & $18.5 \pm 0.1$ & $31.0 \pm 1.4$ & $17.4 \pm 1.4$ \\
\hline TVS $\left(\mathrm{g} \mathrm{kg}^{-1}\right)$ & $21.9 \pm 1.0$ & $12.9 \pm 0.3$ & $23.0 \pm 0.7$ & $11.5 \pm 0.0$ & $22.5 \pm 1.2$ & $10,7 \pm 0.9$ \\
\hline TS/TVS (\%) & 72.0 & 65.5 & 72.4 & 62.4 & 72.5 & 61.7 \\
\hline TSVS (g kg-1) & - & 8.4 & - & 8.6 & - & 7.7 \\
\hline$N_{k}\left(g_{k g}-1\right)$ & 1.9 & 1.7 & 2.1 & 1.6 & 1.7 & 1.7 \\
\hline $\mathrm{N}-\mathrm{NH}_{4}+\left(\mathrm{g} \mathrm{kg}^{-1}\right)$ & 1.3 & 1.3 & nd & 1.6 & nd & 1.2 \\
\hline TOC & 12.7 & 7.5 & 13.3 & 6.7 & 13.1 & 6.2 \\
\hline $\mathrm{C} / \mathrm{N}$ & 7.0 & - & 7.0 & - & 8.0 & - \\
\hline
\end{tabular}

EC: electrical conductivity; TCOD: total chemical oxygen demand; SCOD: soluble chemical oxygen demand; TS: total solids; TVS: total volatile solids; TSVS: total suspended volatile solids; $\mathrm{N}_{\mathrm{k}}$ : Kjeldahl nitrogen; $\mathrm{N}^{-\mathrm{NH}_{4}+}$ : ammoniacal nitrogen; TOC: total organic carbon; $\mathrm{C} / \mathrm{N}$ : carbon/nitrogen ratio; nd: not determined.

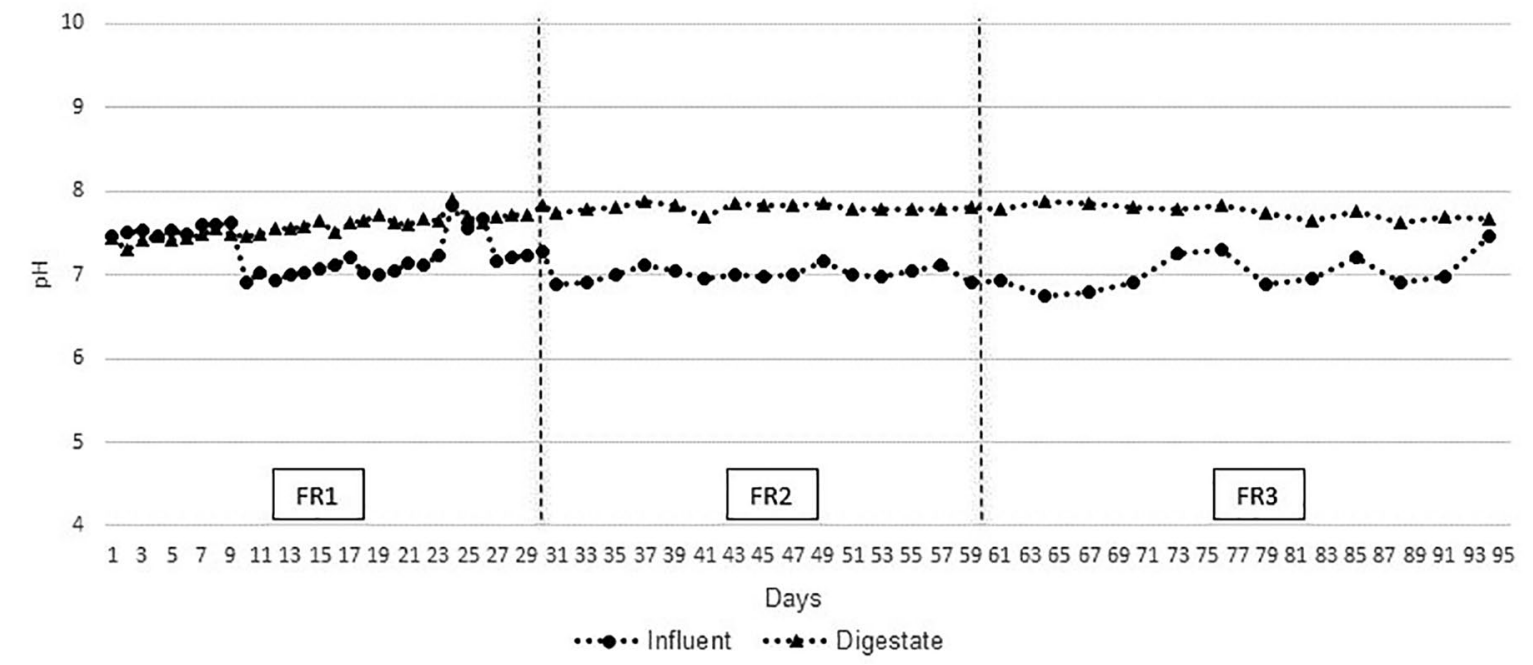

Figure 1. $\mathrm{pH}$ profile.

there was a $32 \%$ increase between FR1 and FR2, followed by a $4 \%$ increase from FR2 to FR3. Between FR1 and FR3, there was a $37 \%$ increase.

Throughout the study of the effect of feeding frequencies (FR2 and FR3), there was a pattern in average biogas daily production, after the load shocks. In the FR2 after each feed load, it was recorded that the GP in the first $24 \mathrm{~h}$ corresponded to $70 \%$ of the cumulative biogas production, while in the FR3, in the same period, the production corresponded to $50 \%$ of the total, and after $48 \mathrm{~h}$ was $35 \%$.

Regarding the GPR, the evolution of the average daily production can be verified, with the value of GPR in the first FR of $0.8 \mathrm{LL}_{\text {reactor }}{ }^{-1} \mathrm{~d}^{-1}$, increasing to $1.9 \mathrm{LL}_{\text {reactor }}{ }^{-1} \mathrm{~d}^{-1}$ in FR2 and ending with $3.0 \mathrm{LL}_{\text {reactor }}{ }^{-1} \mathrm{~d}^{-1}$ in the FR3 trial.

The range and distribution of the regimes with a famine period (FR2 and FR3) are much more similar than the feast regime (FR1), as seen in Figure 3.
Table 2. Operational parameters.

\begin{tabular}{|c|c|c|c|}
\hline $\begin{array}{l}\text { Operational } \\
\text { parameters }\end{array}$ & FR1 & FR2 & FR3 \\
\hline $\mathrm{GP}_{\text {Biogas }}$ (L & $3.50 \pm 0.70$ & $4.20=$ & 4.70 \\
\hline$M P\left(L d^{-1}\right)$ & $2.60 \pm 0.60$ & $3.10 \pm 0.10$ & $3.50 \pm 0.10$ \\
\hline Biogas quality $\left(\% \mathrm{CH}_{4}\right)$ & 73 & 75 & 75 \\
\hline $\operatorname{GPR}_{\text {Biogas }}\left(L L_{\text {reactor }}^{-1} d^{-1}\right)$ & $0.80 \pm 0.20$ & $1.90 \pm 0.12$ & $3.00 \pm 0.47$ \\
\hline SGP (L g TVS-1) & $0.51 \pm 0.11$ & $0.66 \pm 0.05$ & $0.69 \pm 0.11$ \\
\hline $\mathrm{SMP}\left(\mathrm{L} \mathrm{CH}_{4} \mathrm{~g}_{\mathrm{TVS}}^{-1}\right)$ & $0.38 \pm 0.08$ & $0.50 \pm 0.04$ & $0.52 \pm 0.08$ \\
\hline TVS reduction (\%) & 41.10 & 50.00 & 52.40 \\
\hline TCOD reduction (\%) & 38.10 & 54.10 & 62.70 \\
\hline $\operatorname{SELR}\left(d^{-1}\right)$ & $0.38 \pm 0.02$ & $0.32 \pm 0.04$ & $0.38 \pm 0.02$ \\
\hline
\end{tabular}

$\mathrm{GP}_{\text {Biogas: }}$ : daily biogas production; MP: methane production; $\mathrm{CH}_{4}$ : methane; GPR: gas production rate; SGP: specific gas production; TVS: total volatile solids; SMP: specific methane production; TCOD: total chemical oxygen demand; SELR: specific energetic loading rate. 


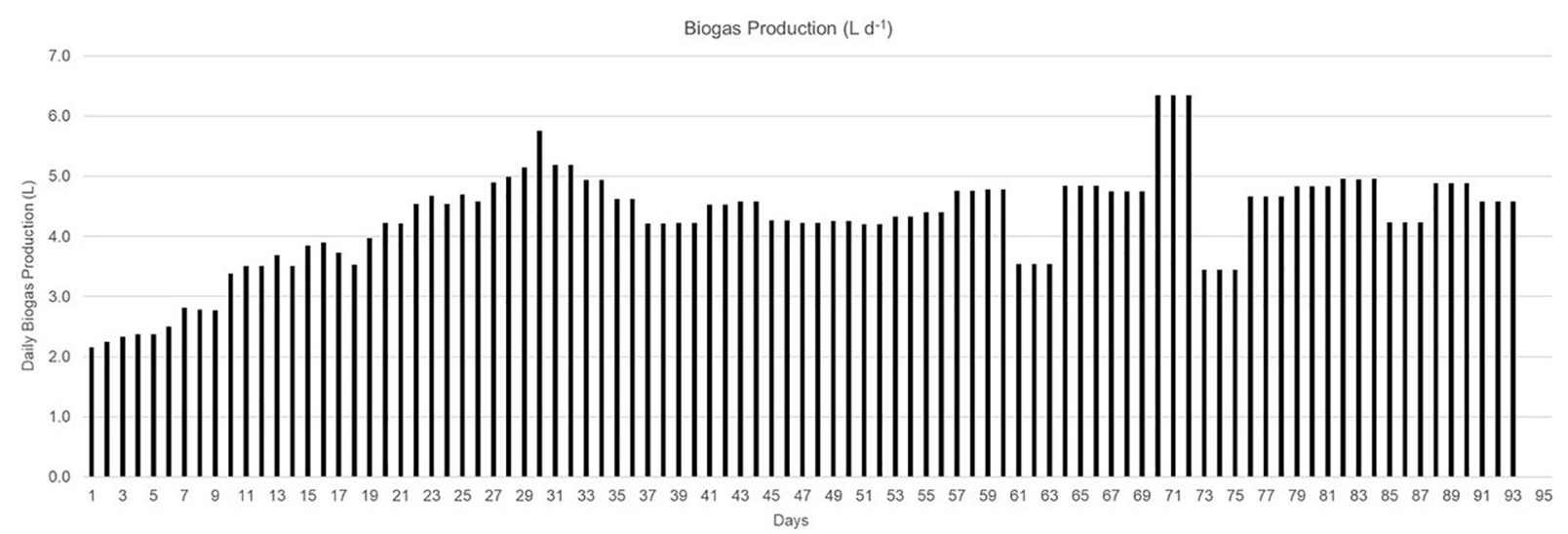

Figure 2. Daily biogas production.

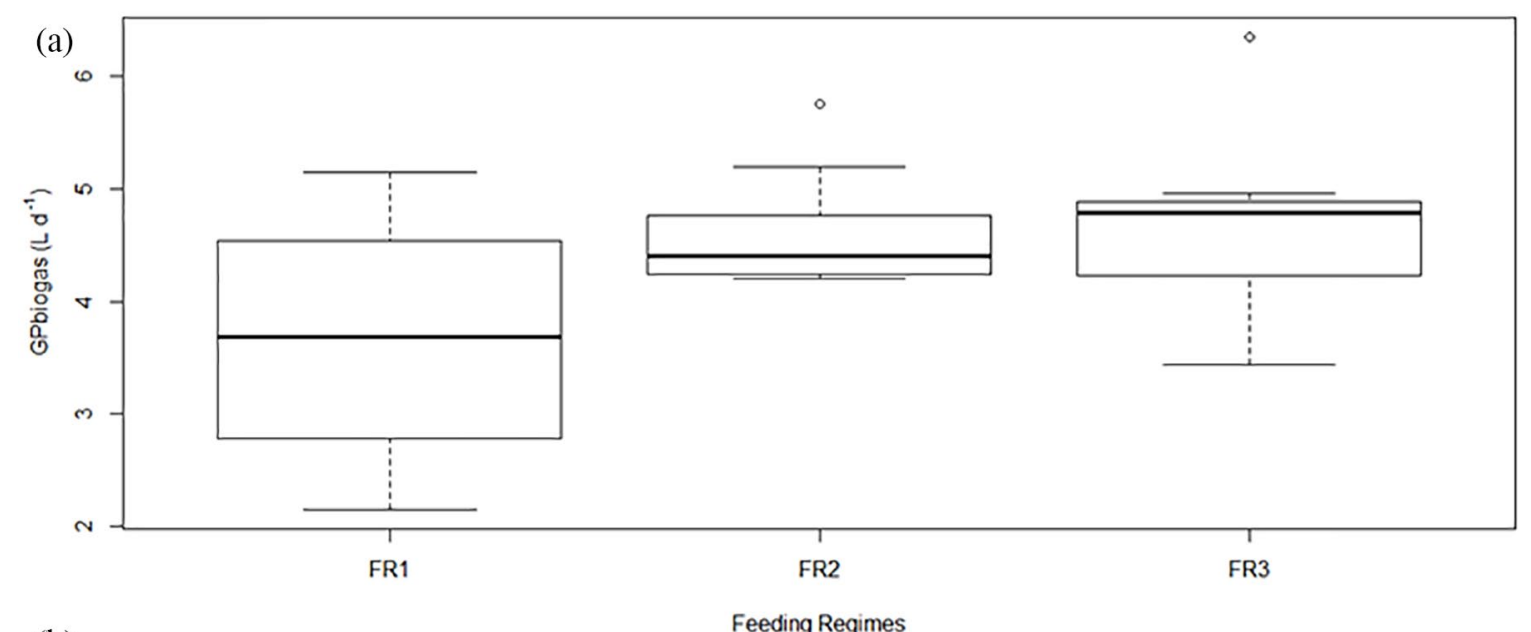

(b)

Feeding Regimes

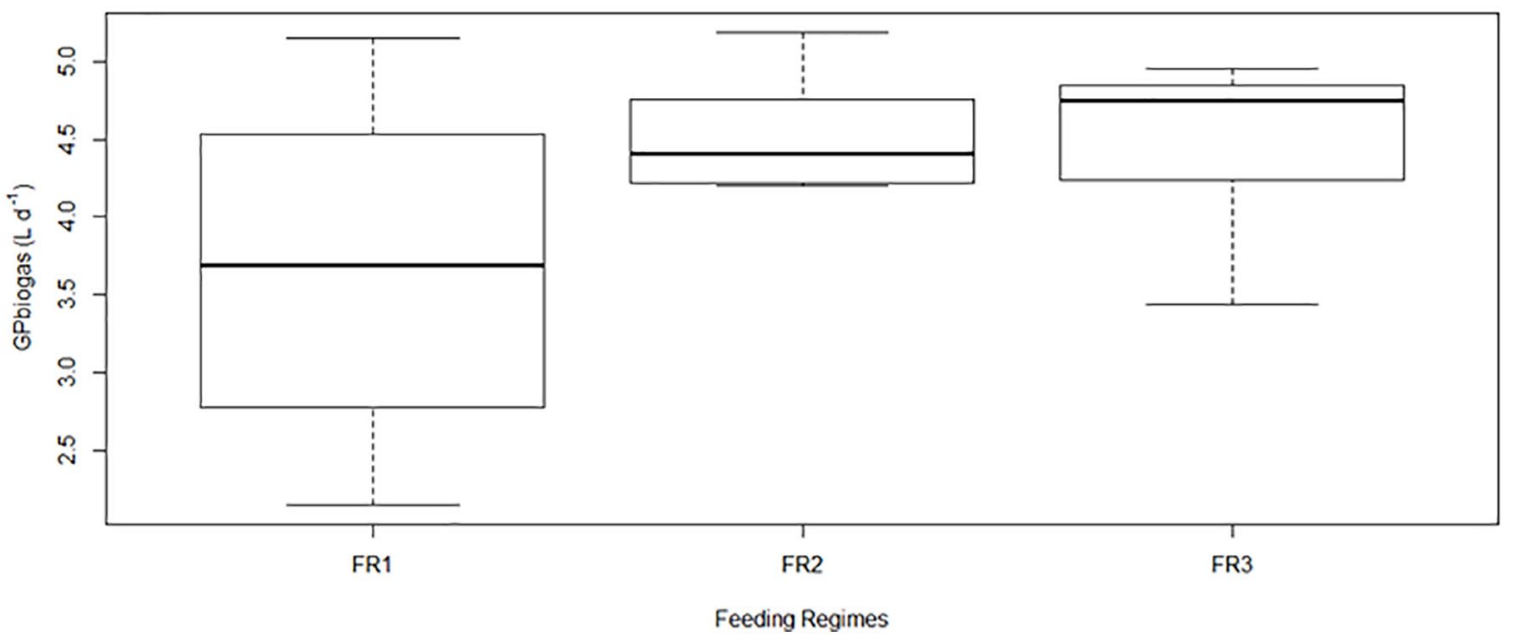

Figure 3. Gas production: boxplots of full data (a) and without outliers (b).

Both FR2 and FR3 have outliers that occur at different times. In FR2, there is only one outlier in the first day, and in FR3 the 10 th, 11 th and 12 th days are all outliers of equal value. The reason for these outliers is suggested to be on account of a stabilisation period between regimes, because the production of biogas becomes more regular after a short decline at the start of the regime. Although this decline lasts for a different number of days in FR2 and FR3, it ends after four loads in both. Removing the outliers improved the distribution of errors, which can be accepted as normal at a 0.1 significance level.

On a first approach, ANOVA had a $p$-value $=9.66 \times 10^{-7}$. The rejection of the null hypothesis indicates that at least one of the means is significantly different, as seen in Figure 4. The Tukey test shows which means are significantly different from each other. 


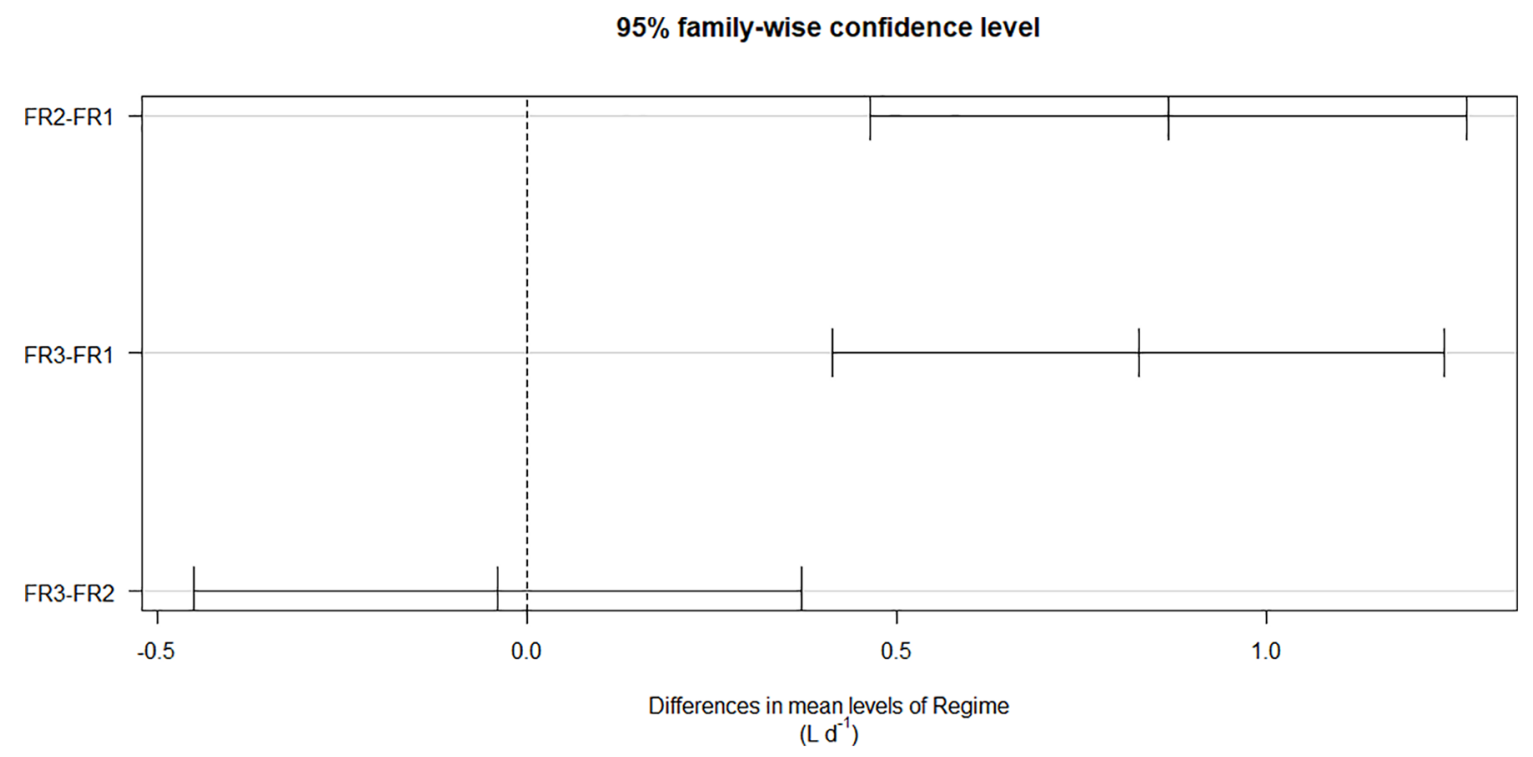

Figure 4. Representation of Tukey's test.

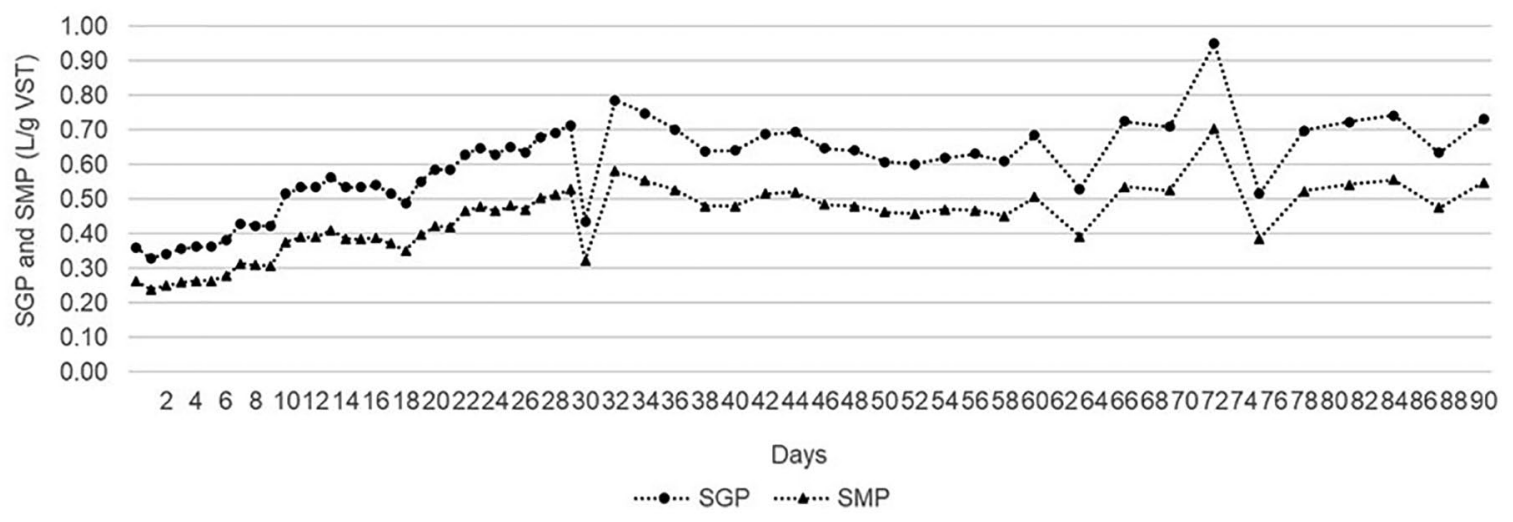

Figure 5. Specific biogas and methane production (L g TVS ${ }^{-1}$ ).

The difference is very close to zero for FR2 and FR3. So, these regimes should not be separate. The Welch $t$-test was then used. This test is represented by a Student's $t$-test statistic of $t=0.3293$ and offers the same conclusion because the $p$-value $=0.7437$, which is much higher than 0.05 . The null hypothesis is not rejected, meaning the second and third regimes did not record a significant difference in means and indicating that a higher famine period does not significantly impact biogas production.

Figure 5 shows the SGP and SMP throughout the AD assays, and it is possible to verify the increasing trend of these parameters. The average value of SGP in FR1 was $0.51 \pm 0.11 \mathrm{Lg} \mathrm{TVS}^{-1}$, and compared to the other regimes there is an approximate increase of $29 \%$ for FR2 and $35 \%$ for FR3. For SMP, values of $0.38 \pm 0.08 \mathrm{LgTVS}^{-1}$ for FR1, $0.50 \pm 0.04 \mathrm{Lg} \mathrm{TVS}^{-1}$ for FR2 and $0.52 \pm 0.08 \mathrm{Lg} \mathrm{TVS}^{-1}$ for FR3 can be observed. An increase of about $32 \%$ from FR1 to FR2 can be observed, followed by a slight increase of $4 \%$ between FR2 and FR3. When comparing FR1 with FR3, an increase of about $37 \%$ can be verified, which proves the increase in quality (methane percentage). There was a slight increase in the quality of biogas from the first to the second FR (from $73 \%$ to $75 \%$ ), with subsequent stabilisation.

Zealand et al. (2017) studied the performance of reactors with different feeding frequencies and for the scenario similar to FR3 obtained an SMP of $0.12 \mathrm{LgTVS}^{-1}$, which means that values obtained in this study are 4.3 times higher than those stated in the literature.

The SELR parameter is the ratio between the organic load of the daily feed (expressed in TCOD) and the amount of biomass inside the reactor (expressed in total suspended volatile solids). It is the concept that the microbial consortium has a maximum bioconversion capacity and if this is exceeded, the reactor may become unstable, resulting in methanogenesis inhibition and even process failure. Therefore, it evaluates the stability of the reactor, which will be unstable for values above $0.4 \mathrm{~d}^{-1}$, and for values below $0.4 \mathrm{~d}^{-1}$ it indicates the possibility of increasing the organic load of the feeding, without causing the failure of the process (Lopes et al., 2017). During the trials, the values determined ranged from $0.32 \pm 0.04$ to $0.38 \pm 0.02$, which suggests that the reactor is stable but that some supervision must be taken so that instability problems do not occur. 
Table 3. Quantification of microorganisms in feeding and digestate.

\begin{tabular}{|c|c|c|c|c|c|c|}
\hline & \multicolumn{3}{|l|}{ Feeding (CFU g ${ }^{-1}$ ) } & \multicolumn{3}{|c|}{ Digestate (CFU g ${ }^{-1}$ ) } \\
\hline & FR1 & FR2 & FR3 & FR1 & FR2 & FR3 \\
\hline E. coli & $1.12 \pm 0.12 \times 10^{5}$ & $6.40 \pm 4.90 \times 10^{3}$ & $6.70 \pm 1.60 \times 10^{3}$ & $<100$ & $<100$ & $<100$ \\
\hline TSAYE & $1.01 \pm 0.11 \times 10^{8}$ & $3.70 \pm 0.60 \times 10^{7}$ & $6.90 \pm 0.20 \times 10^{7}$ & $2.58 \pm 0.78 \times 10^{6}$ & $1.86 \pm 0.04 \times 10^{6}$ & $1.22 \pm 0.13 \times 10^{7}$ \\
\hline MHA & $1.74 \pm 0.14 \times 10^{8}$ & $3.15 \pm 0.05 \times 10^{7}$ & $7.70 \pm 0.10 \times 10^{7}$ & $5.57 \pm 3.28 \times 10^{6}$ & $2.04 \pm 0.18 \times 10^{6}$ & $1.35 \pm 0.10 \times 10^{7}$ \\
\hline Clostridium spp. & $<100$ & $4.00 \pm 0.70 \times 10^{2}$ & $2.45 \pm 0.55 \times 10^{2}$ & $4.00 \pm 0.37 \times 10^{2}$ & $5.05 \pm 0.05 \times 10^{2}$ & $5.00 \pm 1.45 \times 10^{2}$ \\
\hline
\end{tabular}

\section{Microbiological indicators}

The European regulations regarding the microbiological criteria for organic fertilisers are absence of Salmonella in $25 \mathrm{~g}$ and less than $1000 \mathrm{CFU}$ of E. coli per g of fresh material (Regulation (EU) 2019/1009). The pig slurry used to feed the AD reactor met the legal requirement regarding the absence of Salmonella in $25 \mathrm{~g}$. However, the level of $E$. coli in the pig slurry (initially $1.12 \times 10^{5}$ $\mathrm{CFU} / \mathrm{g}$ ) prevented its possible use as an organic amendment. During the storage of the pig slurry, a significant decrease $(p<0.1)$ in the count of $E$. coli in the feeding from FR1 to FR2 and FR1 to FR3 was observed, although the legal criterion was not reached (Table 3). This may reflect the alteration of the slurry's microbiota induced by the occurrence of partial anaerobic conditions during storage. In fact, storage seems to be functioning as a preconditioning of the slurry for $\mathrm{AD}$, creating less favourable conditions or even inhibiting the growth of $E$. coli.

Although the $\mathrm{AD}$ process results in the disposal of wastes, the recycling of nutrients and methane production, concerns exist as to whether $\mathrm{AD}$ can inactivate pathogens. In the three FRs tested, the total E. coli in the feeding was reduced from $1.12 \pm 1.15$ $\times 10^{4} \mathrm{CFUg}^{-1}$ (FR1), $6.40 \pm 4.90 \times 10^{3} \mathrm{CFUg}^{-1}$ (FR2) and $6.70 \pm 1.60 \times 10^{3} \mathrm{CFUg}^{-1}$ (FR3) to less than $100 \mathrm{CFU} \mathrm{g}^{-1}$ in the digestate (Table 3), in compliance with the legal requirements described previously (less than $1 \times 10^{3} \mathrm{CFU} \mathrm{g}^{-1}$ ). These results show that for the three FRs used, the obtained digestate was sanitised and, therefore, in conformity with the microbiological requirements for its use for agricultural valorisation. Previously, in a review summary of the inactivation of different pathogens by different treatments, Franke-Whittle and Insam (2013) also reported the ability of both mesophilic and thermophilic $\mathrm{AD}$ in the inactivation of $E$. coli.

Another microbiological indicator evaluated was the level of total anaerobic mesophiles. Two different culture media were used: one nutritionally rich (TSAYE) and the other nutritionally poorer (MHA), aiming to target anaerobic bacteria with different nutritional requirements. Notwithstanding, the evolution of the number of total anaerobic mesophiles in both media was similar, showing a significant decreasing trend $(p<0.1$ and $p<0.05$, respectively) between the feedings and the digestates (Table 3). Culture-based techniques have an inherent limitation because only the viable population will grow to produce colonies, while others do not proliferate as a result of their complex syntrophic and symbiotic relationships. This results in an underestimation of the total number of microorganisms by plate count techniques. That is why methods based on metagenomics have been used to unravel the AD microbiome (Zhang et al., 2019). Nevertheless, this decrease in the number of culturable microorganisms from feeding to digestate reflects the profound changes that occur during the $\mathrm{AD}$, most probably with the proliferation of a large number of non-culturable species that are determinant for biogas production in detriment of those that are culturable.

Several laboratory-scale studies have shown a positive influence of discontinuous FRs on process performance and functional stability associated with shifts in the microbial community. Mulat et al. (2016) registered a larger amount of biogas produced after feeding the reactors less frequently and found differences in the composition of the bacterial community with the FR. Bonk et al. (2018) reported that communities with a higher share of Methanosarcina showed higher process stability and suggested that discontinuous feeding can purposefully increase the share of these microorganisms.

The genus Clostridium, composed of strict/facultative anaerobes, has been associated with the stable performance of the $\mathrm{AD}$ process. As it is acknowledged, most Clostridium species are culturable. In this work, their numbers were determined both in feeding and in digestate. The results showed that there was an increase in the numbers of Clostridium spp. in the feeding from FR1 to FR2 and from FR1 to FR3 (overall, from less than $10 \mathrm{CFU} \mathrm{g}^{-1}$ to more than $2.45 \pm 5.50 \times 10^{1} \mathrm{CFU} \mathrm{g}^{-1}$ ) (Table 3), reflecting once again the occurrence of partial anaerobiosis during storage of the slurry. While in FR2 and FR3 there were no significant differences $(p>0.05)$ between these numbers in the feeding and in the digestate, in FR1 the numbers of viable Clostridium spp. in the digestate were significantly higher $(p>0.05)$ than in feeding (Table 3 ). These results are supported by those obtained by Costa et al. (2017), reporting that mesophilic AD caused an increase in the Clostridia population initially present in the pig slurry, and further confirm the connection with AD stability. In an industrial-scale thermophilic biogas plant converting maize and barley silage in co-digestion with cattle and pig manure, by using a polyphasic approach, Maus et al. (2016) found Clostridia within the three genera of most metabolically active fermentative bacteria. Joyce et al. (2018) highlighted the functional importance of Clostridia during $\mathrm{AD}$ of the grass and suggest that members of this genus can be investigated with a view to optimising $\mathrm{AD}$.

\section{Conclusion}

The results of this study allowed a more in-depth understanding of the effect of feast and famine in AD. The decrease in feeding frequencies and, consequently, the increase in load shocks 
showed a positive effect on biogas and bio- $\mathrm{CH}_{4}$ production. A positive pattern in the production of bio- $\mathrm{CH}_{4}$ was evident in the regimes where starvation was induced (FR2 and FR3), which is an interesting fact as it suggests the adaptation of the microbiota to variations in the operational parameters of the $\mathrm{AD}$ - namely, slurry storage time and reactor feeding frequency. In fact, with lower feeding frequencies, daily biogas and bio- $\mathrm{CH}_{4}$ flows were higher compared to feeds that were more frequent, which is supported by the fact that a higher famine period does not significantly impact biogas production.

Regarding the AD microbiological indicators evaluated, the hygienisation of the digestate could be achieved in mesophilic regime, thus fulfilling the legal requirement $\left(<1000 \mathrm{CFU} \mathrm{g}^{-1}\right)$ for agronomic valorisation. Moreover, Clostridium spp. was shown to be a potential microbiological key indicator of the $\mathrm{AD}$, since its concentration increased from feast to famine (FR1 to FR3), corresponding to an increased production of bio- $\mathrm{CH}_{4}$ over the three regimes studied.

These results prove the potential of AD for not only obtaining biogas of high-quality bio- $\mathrm{CH}_{4}$, a clean, renewable energy with low GHG emissions, but also for the safe management of pig slurry for agronomic valorisation. By allowing the production of bioenergy from the optimised management of livestock effluents, the $\mathrm{AD}$ technology constitutes an incontrovertible opportunity to meet the challenges of future sustainable energy systems in the agricultural sector. This work emphasises the possibility of enhancement AD technology to promote economic and social development in the pig manure chain.

\section{Declaration of conflicting interests}

The authors declared no potential conflicts of interest with respect to the research, authorship, and/or publication of this article.

\section{Funding}

The authors received no financial support for the research, authorship, and/or publication of this article.

\section{ORCID iD}

I Silva (iD https://orcid.org/0000-0001-9341-092X

\section{References}

Achinas S, Achinas V and Euverink GJW (2017) A technological overview of biogas production from biowaste. Engineering 3: 299-307.

American Public Health Association (APHA) (2012) Standard Methods for the Examination of Water and Wastewater. 22nd ed. Washington, DC: American Public Health Association, American Water Works Association, Water Environment Federation.

Bonk F, Popp D, Welnrich S, et al. (2018) Intermittent fasting for microbes: How discontinuous feeding increases functional stability in anaerobic digestion. Biotechnology for Biofuels 11: 274.

Boyd RD, Castro GC and Cabrera RA (2002) Nutrition and management of the sow to maximize lifetime productivity. Advances in Pork Production 13: 47-59.

Bres P, Beily ME, Young BJ, et al. (2018) Performance of semi-continuous anaerobic co-digestion of poultry manure with fruit and vegetable waste and analysis of digestate quality: A bench scale study. Waste Management 82: $276-284$.
Chen S, Cheng H, Wyckoff KN, et al. (2016) Linkages of Firmicutes and Bacteroidetes populations to methanogenic process performance. Journal of Industrial Microbiology and Biotechnology 43: 771-781.

Chiu SLH, Lo IMC, Woon KS, et al. (2016) Life cycle assessment of waste treatment strategy for sewage sludge and food waste in Macau: Perspectives on environmental and energy production performance. The International Journal of Life Cycle Assessment 21: 176-189.

Chojnacka K, Moustakas K and Witek-Krowiak A (2020) Bio-based fertilizers: A practical approach towards circular economy. Bioresource Technology 295: 122223.

Costa A, Gusmara C, Gardoni D, et al. (2017) The effect of anaerobic digestion and storage on indicator microorganisms in swine and dairy manure. Environmental Science and Pollution Research 24: 2413524146.

de Jonge N, Moset V, Møller HB, et al. (2017) Microbial population dynamics in continuous anaerobic digester systems during start up, stable conditions and recovery after starvation. Bioresource Technology 232: 313-320.

Duarte E, Fragoso R, Smozinski N, et al. (2020) Enhancing bioenergy recovery from agro-food biowastes as a strategy to promote circular bioeconomy. Journal of Sustainable Development of Energy, Water and Environment Systems. Epub ahead of print July 2020. DOI: 10.13044/j. sdewes.d8.0320.

EU (2019) Regulation (EU) 2019/1009 of the European Parliament and of the Council of 5 June 2019. Official Journal of the European Union 170 .

Fox J and Weisberg S (2019) An R Companion to Applied Regression. 3rd ed. Thousand Oaks, CA: SAGE.

Franke-Whittle IH and Insam H (2013) Treatment alternatives of slaughterhouse wastes, and their effect on the inactivation of different pathogens: A review. Critical Reviews in Microbiology 39: 139-151.

Joyce A, Ijaz UZ, Nzeteu C, et al. (2018) Linking microbial community structure and function during the acidified anaerobic digestion of grass. Frontiers in Microbiology 9: 540.

Kangle KM, Kore SV, Kore VS, et al. (2011) Recent trends in anaerobic codigestion: A review. Universal Journal of Environmental Research and Technology 2: 210-219.

Khan MA, Ngo HH, Guo WS, et al. (2016) Optimization of process parameters for production of volatile fatty acid, biohydrogen and methane from anaerobic digestion. Bioresource Technology 219: 738-748.

Lin Q, Vrieze JD, He G, et al. (2016) Temperature regulates methane production through the function centralization of microbial community in anaerobic digestion. Bioresource Technology 216: 150-158.

Lopes M, Baptista P, Duarte E, et al. (2017) Enhanced biogas production from anaerobic co-digestion of pig slurry and horse manure with mechanical pre-treatment. Environmental Technology 40: 1289-1297.

Lv Z, Wu X, Zhou B, et al. (2019) Effect of one step temperature increment from mesophilic to thermophilic anaerobic digestion on the linked pattern between bacterial and methanogenic communities. Bioresource Technology 292: 121968.

Maus I, Koeck DE, Cibis KG, et al. (2016) Unraveling the microbiome of a thermophilic biogas plant by metagenome and metatranscriptome analysis complemented by characterization of bacterial and archaeal isolates. Biotechnology for Biofuels 9: 171.

Mulat DG, Jacobi HF, Feilberg A, et al. (2016) Changing feeding regimes to demonstrate flexible biogas production: Effects on process performance, microbial community structure, and methanogenesis pathways. Applied and Environmental Microbiology 82: 438-449.

Ning J, Zhou M, Pan X, et al. (2019) Simultaneous biogas and biogas slurry production from co-digestion of pig manure and corn straw: Performance optimization and microbial community shift. Bioresource Technology 282: $37-47$.

R Core Team (2019) R: A language and environment for statistical computing. Vienna: R Foundation for Statistical Computing. Available at: https://www.R-project.org/ (accessed 19 March 2020).

Ros M, Filho JSO, Murcia MDP, et al. (2017) Mesophilic anaerobic digestion of pig slurry and fruit and vegetable waste: Dissection of the microbial community structure. Journal of Cleaner Production 156: $757-765$. 
Shi L, Simplicio WS, Wu G, et al. (2018) Nutrient recovery from digestate of anaerobic digestion of livestock manure: A review. Water Pollution 4: 74-83.

Srisowmeya G, Chakravarthy M and Devi GN (2019) Critical considerations in two-stage anaerobic digestion of food waste - A review. Renewable and Sustainable Energy Reviews 119: 109587.

Wainaina S, Kumar M, Sarsaiya S, et al. (2020) Resource recovery and circular economy from organic solid waste using aerobic and anaerobic digestion technologies. Bioresource Technology 301: 122778.

Yang J, Wang D, Luo Z, et al. (2019) Anaerobic mono-digestion of pig manure in a leach bed coupled with a methanogenic reactor: Effects of the filter media. Journal of Cleaner Production 234: 1094-1101.
Zhang L, Loh K, Lim JW, et al. (2019) Bioinformatics analysis of metagenomics data of biogas-producing microbial communities in anaerobic digesters: A review. Renewable and Sustainable Energy Reviews 100: $110-126$.

Zhang W, Lang Q, Wu S, et al. (2014) Anaerobic digestion characteristics of pig manures depending on various growth stages and initial substrate concentration in a scaled pig farm in Southern China. Bioresource Technology 156: 63-69.

Zealand AM, Roskilly AP and Graham DW (2017) Effect of feeding frequency and organic loading rate on biomethane production in the anaerobic digestion of rice straw. Applied Energy 207: 156-165. 